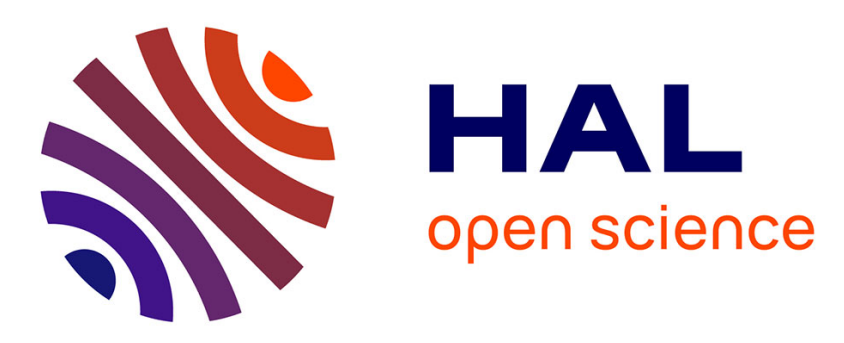

\title{
A fast semi-analytical method for computing the response of railway tracks on nonlinear foundations
}

Tien Hoang, Denis Duhamel, Gilles Forêt, Honoré P. Yin, G Cumunel, P Joyez, R Caby

\section{- To cite this version:}

Tien Hoang, Denis Duhamel, Gilles Forêt, Honoré P. Yin, G Cumunel, et al.. A fast semi-analytical method for computing the response of railway tracks on nonlinear foundations . COMPDYN 2015, May 2015, Hersonissos ,Crete Island, Greece. hal-01266403

\section{HAL Id: hal-01266403 \\ https://hal.science/hal-01266403}

Submitted on 2 Feb 2016

HAL is a multi-disciplinary open access archive for the deposit and dissemination of scientific research documents, whether they are published or not. The documents may come from teaching and research institutions in France or abroad, or from public or private research centers.
L'archive ouverte pluridisciplinaire HAL, est destinée au dépôt et à la diffusion de documents scientifiques de niveau recherche, publiés ou non, émanant des établissements d'enseignement et de recherche français ou étrangers, des laboratoires publics ou privés. 


\title{
A FAST SEMI-ANALYTICAL METHOD FOR COMPUTING THE RESPONSE OF RAILWAY TRACKS ON NONLINEAR FOUNDATIONS
}

\author{
T. Hoang ${ }^{1}$, D. Duhamel ${ }^{1}$, G. Foret ${ }^{1}$, H. Yin ${ }^{1}$, G. Cumunel ${ }^{1}$, P. Joyez ${ }^{2}$ and R. Caby ${ }^{2}$ \\ ${ }^{1}$ Université Paris-Est, Navier (UMR 8205 ENPC-IFSTTAR-CNRS) \\ Ecole Nationale des Ponts et Chaussées \\ 6 et 8 Avenue Blaise Pascal, Cité Descartes, Champs-sur-Marne \\ 77455 Marne-la-Vallée Cedex 2, France \\ e-mail: \{tien.hoang, denis.duhamel, gilles.foret, hai-ping.yin, gwendal.cumunel $\} @$ enpc.fr \\ ${ }^{2}$ Eurotunnel Group \\ BP no. 69, 62904 Coquelles Cedex, France \\ e-mail: \{patrick.joyez, raphael.caby\}@eurotunnel.com
}

Keywords: Railway, Nonlinear Foundation, Dynamics, Iteration Procedure

\begin{abstract}
The nonlinear vibration of railway tracks is a subject of some recent investigations. A main source of non-linearity comes from the railway foundations. For example, ballast and its lower layers or support systems of non-ballasted railway could have nonlinear behaviors. Models of beam under moving forces are often used for this dynamic system, and then the models are solved by numerical method or perturbation technique for some special nonlinear cases. This communication present a new method for calculating the response of railway tracks under moving trains loads. Based an analytical model of periodically supported beam, this model holds for all kinds of nonlinear foundations. Then, by using harmonic balance techniques and iteration procedures, a new method is developed to calculate the response of the model provided that the loading forces form a periodic impulse series. This kind of loading force represents charges of moving trains with equal mass wagons. This method is demonstrated to converge to the analytic solution of the model in case of linear foundation. Then, it is applied to bilinear and nonlinear foundation as examples. The results show that the nonlinear parameters of foundation have a strong influence on the railways track responses. This semi-analytical method is simple and could be efficient to compute the nonlinear vibrations of railway tracks.
\end{abstract}




\section{INTRODUCTION}

The nonlinear vibration of railway tracks is a subject of many investigations [2-9]. A main source of non-linearity comes from the railway foundations. For example, ballast and its lower layers or support systems of non-ballasted railway could have nonlinear behaviours. Models of beam on continuous or periodical supports under moving forces are often used for this dynamic system.

The first model was developed by Fryba [10] by considering beams on an elastic foundation. Then this model has been developed for other linear foundations [11-14]. In order to take into account the discrete supports, Mead $[15,16]$ presented periodically supported beams for railway tracks. This model is also developed by other authors for different kind of linear supports and moving forces [17-21]. Although the analytical methods are well developed for linear cases, these methods can not be easily applied to nonlinear foundations. An alternative is to use numerical methods [2-7] or perturbation techniques [8, 9]. However, the perturbation techniques have some limitations when applied to general cases.

We propose here a semi-analytical method for solving the problem of the dynamics of railway tracks on nonlinear foundations. Based on the model of periodically supported beam by Hoang et al. [1], a numerical method is developed for nonlinear behaviours. This method approaches Fourier series of the response by using harmonic balance techniques and an iteration procedure $[22,23]$. The method is then compared to analytical solutions for linear foundation situations. The bilinear and nonlinear constitutive laws are considered as examples for the method. These examples show that this is a simple way to approach the responses of the system.

\section{MODEL OF RAILWAY ON NONLINEAR FOUNDATION}

\subsection{Reduced relation between force and displacement of railway sleepers}

Here we consider a railway track with sleepers distributed periodically in a nonlinear foundation whose reaction force is characterized by a function $f\left(w, w^{\prime}\right), w(t)$ is the displacement of the sleeper as shown in figure 1 . The rail is subjected to moving forces $Q_{j}$ characterized by the distance to the first moving force $D_{j}(j=1 . . K$ with $K$ is the number of moving forces).

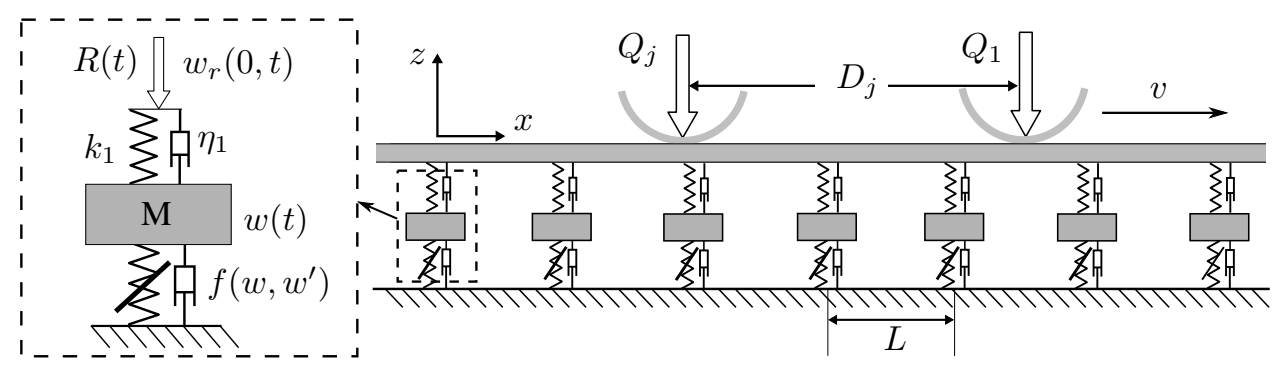

Figure 1: Periodically supported beam subjected to moving forces

When the rail is modelled by a Euler-Bernoulli beam, the response of railway tracks is governed by the following dynamical equation:

$$
E I \frac{\partial^{4} w_{r}(x, t)}{\partial x^{4}}+\rho S \frac{\partial^{2} w_{r}(x, t)}{\partial t^{2}}-F(x, t)=0
$$

where $F(x, t)$ is the total force (moving forces and reaction forces) acting on the beam, $\rho, E$ are the density, the Young's modulus and $S, I$ are the section and the longitudinal inertia of the rail. 
Only the stationary response of the system is considered and the reaction forces of all sleepers are described by a same function but with a delay equal to the time for a load moving from a support to an other (so-called "periodic condition"). This condition leads to a description of the total force as the following:

$$
F(x, t)=\sum_{n=-\infty}^{\infty} R\left(t-\frac{x}{v}\right) \delta(x-n L)-\sum_{j=1}^{K} Q_{j} \delta\left(x+D_{j}-v t\right)
$$

From equation (1) and (2), by using the Fourier transform and Dirac comb propriety (see [1]), we deduce a general relation between the Fourier transform of the vertical displacement $\hat{w}_{r}(0, \omega)$ and of the reaction forces $\hat{R}(\omega)$ of the rail at the sleeper position as the following:

$$
\hat{w}_{r}(0, \omega)=\hat{R}(\omega) \eta_{E}(\omega)-\sum_{j=1}^{K} \frac{Q_{j} e^{-i \omega \frac{D_{j}}{v}}}{v E I\left[\left(\frac{\omega}{v}\right)^{4}-k_{b}^{4}\right]}
$$

with $k_{b}=\sqrt[4]{\frac{\rho S \omega^{2}}{E I}}$ and $\eta_{E}(\omega)$ given by:

$$
\eta_{E}(\omega)=\frac{1}{4 k_{b}^{3} E I}\left[\frac{\sin \left(L k_{b}\right)}{\cos \left(L k_{b}\right)-\cos \left(L \frac{\omega}{v}\right)}-\frac{\sinh \left(L k_{b}\right)}{\cosh \left(L k_{b}\right)-\cos \left(L \frac{\omega}{v}\right)}\right]
$$

For a linear foundation, an analytic solution could be deduced from this equation and the constitutive law of the foundation. In other cases, we can not solve analytically this system. The next section will introduce a model developed from equation (3) for the dynamics of sleepers on a nonlinear foundation. Then, a new numerical method based on harmonic balance techniques and iteration procedures will be used to solve the dynamic equation. Finally, the method is applied to the foundations with linear and nonlinear behaviours. The comparison shows that the numerical method agrees with the analytical results in case of linear behaviour. For other cases, the numerical method shows well the effects of nonlinearities on the response.

\subsection{Dynamical equation of railway sleepers on nonlinear foundation}

Consider the system of sleepers and foundation as shown in figure 1. This system contains a linear part corresponding to the rail pad (upper the sleeper) and a nonlinear part corresponding to the foundation (under the sleeper). Here $\eta_{1}, k_{1}$ are the damping and spring coefficients of rail $\operatorname{pad} ; w, w^{\prime}$ are the vertical displacement and the velocity of the sleeper and $f\left(w, w^{\prime}\right)$ is the force acting on the foundation.

The displacement of the sleeper is governed by the following equation:

$$
M w^{\prime \prime}(t)+\eta_{1} w^{\prime}(t)+k_{1} w+f\left(w, w^{\prime}\right)=\eta_{1} w_{r}^{\prime}(0, t)+k_{1} w_{r}(0, t)
$$

where prime stands for the derivation in time $t$ and $M$ is the mass of the railway sleeper. In addition, the reaction force of the sleeper on the rail is given by:

$$
R(t)=-\eta_{1}\left[w_{r}(0, t)-w(t)\right]^{\prime}-k_{1}\left(w_{r}(0, t)-w(t)\right)
$$

By taking the Fourier transform of (5), we obtain:

$$
\hat{R}(\omega)=-A(\omega)\left[\hat{w}_{r}(0, \omega)-\hat{w}(\omega)\right]
$$


where $A(\omega)=i \omega \eta_{1}+k_{1}$ (this is the frequency stiffness of the rail pad). By injecting the last equation into equation (3), we have:

$$
\hat{w}_{r}(0, \omega)=\frac{A(\omega) \eta_{E}(\omega)}{1+A(\omega) \eta_{E}(\omega)} \hat{w}(\omega)-\frac{\Gamma(\omega)}{v E I} \sum_{j=1}^{K} Q_{j} e^{-i \omega \frac{D_{j}}{v}}
$$

with $\Gamma(\omega)=\left\{\left(1+A(\omega) \eta_{E}(\omega)\right)\left[\left(\frac{\omega}{v}\right)^{4}-k_{b}^{4}\right]\right\}^{-1}$.

Making the Fourier transform and then the inverse Fourier transform of the right term of equation (4) leads to the following result:

$$
\eta_{1} w_{r}^{\prime}(0, t)+k_{1} w_{r}(0, t)=\frac{1}{2 \pi} \int_{-\infty}^{\infty} A(\omega) \hat{w}_{r}(0, \omega) e^{i \omega t} d \omega
$$

By injecting $\hat{w}_{r}(0, \omega)$ in equation (6) into the last equation and then the obtained expression into equation (4), one can write:

$$
\begin{array}{r}
w^{\prime \prime}+\beta w^{\prime}+\omega_{0}^{2} w+g\left(w, w^{\prime}\right)=\frac{1}{2 \pi M} \int_{-\infty}^{\infty} \frac{A^{2}(\omega) \eta_{E}(\omega) e^{i \omega t}}{1+A(\omega) \eta_{E}(\omega)} \hat{w}(\omega) d \omega \\
-\frac{1}{2 \pi M} \int_{-\infty}^{\infty} \frac{A(\omega) \Gamma_{E}(\omega)}{v E I} \sum_{j=1}^{K} Q_{j} e^{-i \omega \frac{D_{j}}{v}} e^{i \omega t} d \omega
\end{array}
$$

where $g\left(w, w^{\prime}\right)=\frac{f\left(w, w^{\prime}\right)}{M}, \omega_{0}^{2}=\frac{k_{1}}{M}$ and $\beta=\frac{\eta_{1}}{M}$.

Equation (8) is the dynamical equation of the sleeper. This equation is similar to that of nonlinear oscillators but contains terms of the interaction between the rail and the sleepers on the right of the equation. In order to simplify this coupling terms but only periodical solution of $w(t)$ is considered but the general nonlinear function $f\left(w, w^{\prime}\right)$ is kept. This response occurs when the moving forces $Q_{j}$ are a periodic series of forces (see [1]) which is presented in next section.

\subsection{Loads of a train as an impulse train}

When the charges of each wagon of the train equal a given load $\left(Q_{j}=Q\right)$ and there is a great number of wagons so that the periodical solution could be considered, the load of a train can be approximated by an impulse train with a distance from a reference impulse given by:

$$
D_{j}= \begin{cases}j H & \text { for front wheels } \\ j H+D & \text { for back wheels }\end{cases}
$$

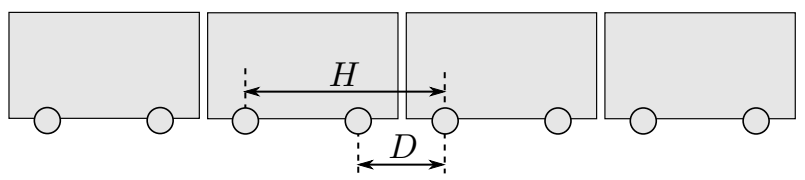

Figure 2: Charge of a train as a periodical series of loads 
where $H$ and $D$ are the length of each wagon and distance between the font and the back wheel of a boogie. Using the propriety of Dirac comb, one can write:

$$
\sum_{j=-\infty}^{\infty} Q_{j} e^{-i \omega \frac{D_{j}}{v}}=\frac{2 \pi v Q}{H}\left(1+e^{-i \omega \frac{D}{v}}\right) \sum_{n=-\infty}^{\infty} \delta\left(\omega+\frac{2 \pi v}{H} n\right)
$$

By injecting the last equation into the last term of equation (8), we obtain:

$$
\frac{1}{2 \pi M} \int_{-\infty}^{\infty} \frac{A(\omega) \Gamma}{v E I} \sum_{j} Q_{j} e^{-i \omega \frac{D_{j}}{v}} e^{i \omega t} d \omega=\sum_{n} \frac{Q\left(1+e^{-i \frac{D}{v} \omega_{n}}\right) A\left(\omega_{n}\right) \Gamma\left(\omega_{n}\right) e^{i \omega_{n} t}}{M H E I}
$$

with $\omega_{n}=2 \pi n \frac{v}{H}$.

The last equation describes a periodic function of harmonics $\omega_{n}$. Thus, we can find a periodical solution of $w(t)$ in Fourier series form:

$$
w(t)=\sum_{n} c_{n} e^{i \omega_{n} t}
$$

where $\left\{c_{n}\right\}$ are Fourier coefficients of $w(t)$ given by:

$$
c_{n}=\frac{1}{T} \int_{-T / 2}^{T / 2} w(t) e^{-i \omega_{n} t} d t \quad \text { with } \quad T=\frac{H}{v}
$$

Thus, we have:

$$
\hat{w}(\omega)=2 \pi \sum_{n} c_{n} \delta\left(\omega-\omega_{n}\right)
$$

By injecting the last equation into the first term on the right side of (8), we get:

$$
\frac{1}{2 \pi M} \int_{-\infty}^{\infty} \frac{A^{2}(\omega) \eta_{E}(\omega) e^{i \omega t}}{1+A(\omega) \eta_{E}(\omega)} \hat{w}(\omega) d \omega=\frac{1}{M} \sum_{n} \frac{A^{2}\left(\omega_{n}\right) \eta_{E}\left(\omega_{n}\right)}{1+A\left(\omega_{n}\right) \eta_{E}\left(\omega_{n}\right)} c_{n} e^{i \omega_{n} t}
$$

Thus, equation (8) becomes:

$$
w^{\prime \prime}+\beta w^{\prime}+\omega_{0}^{2} w+g\left(w, w^{\prime}\right)=\sum_{n} c_{n} P_{n} e^{i \omega_{n} t}-\sum_{n} F_{n} e^{i \omega_{n} t}
$$

where:

$$
P_{n}=\frac{A^{2}\left(\omega_{n}\right) \eta_{E}\left(\omega_{n}\right)}{M\left[1+A\left(\omega_{n}\right) \eta_{E}\left(\omega_{n}\right)\right]} \quad \text { and } \quad F_{n}=\frac{Q\left(1+e^{-i \omega_{n} \frac{D}{v}}\right)}{M H E I} A\left(\omega_{n}\right) \Gamma\left(\omega_{n}\right)
$$

Particularly, we have: $P_{0}=\frac{k_{1}}{M}=\omega_{0}^{2}$ and $F_{0}=\frac{2 Q L}{M H}$.

Thus, we reduce (8) which is a general dynamical equation of the railway sleeper to a simple equation with characteristic parameters $P_{n}, F_{n}$. In fact, we see that $F_{n}$ corresponds to the charges of the train affecting on the sleeper and $P_{n}$ corresponds to the coupling of the sleeper with the rail and other sleepers. In the next section, we will present a numerical method for this equation and then consider some examples of foundations. 


\section{SEMI-ANALYTICAL METHOD}

Taking Fourier coefficients of equation (15) leads to the following result:

$$
\frac{1}{T} \int_{-T / 2}^{T / 2}\left(w^{\prime \prime}+\beta w^{\prime}+\omega_{0}^{2} w\right) e^{-i \omega_{n} t} d t+\frac{1}{T} \int_{-T / 2}^{T / 2} g\left(w, w^{\prime}\right) e^{-i \omega_{n} t} d t=c_{n} P_{n}-F_{n}
$$

By injection of equation (12) to the last equation, we obtain:

$$
-\omega_{n}^{2} c_{n}+i \beta \omega_{n} c_{n}+\omega_{0}^{2} c_{n}+\frac{1}{T} \int_{-T / 2}^{T / 2} g\left(w, w^{\prime}\right) e^{-i \omega_{n} t} d t=c_{n} P_{n}-F_{n}
$$

where $g\left(w, w^{\prime}\right)=f\left(w, w^{\prime}\right) / M$ with $w, w^{\prime}$ given by equation (12):

$$
w(t)=\sum_{n} c_{n} e^{i \omega_{n} t}, \quad w^{\prime}(t)=\sum_{n} i \omega_{n} c_{n} e^{i \omega_{n} t}
$$

Hence, equation (17) forms a system of nonlinear equations of variable $\left\{c_{n}\right\}$. In general, we can not find the analytical solution of this equation. By using harmonic balance techniques and iteration procedure, we will look at an approximation of the solution $w(t)$ for the $m$ first harmonics in the following form:

$$
w_{m k}(t)=\sum_{n=-m}^{m} c_{n k} e^{i \omega_{n} t} \quad \forall k \geq 1
$$

Here we take $\forall n, c_{n 1}=0$. We built series $\left\{c_{n k}\right\}$ such that $c_{n k} \rightarrow c_{n}$ when $k, m \rightarrow \infty$ by inserting an evolution index $k$ in equation (17). Such a series $\left\{c_{n k}\right\}$ is given by the following equations:

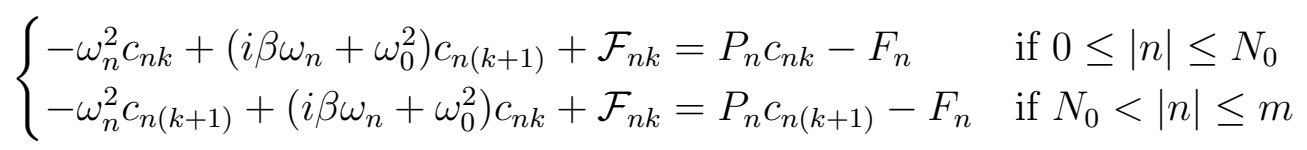

where $N_{0}$ is defined for the convergence of the solution (it normally depends on force $f\left(w, w^{\prime}\right)$ ) and $\mathcal{F}_{n k}$ is calculated by:

$$
\mathcal{F}_{n k}=\frac{1}{T} \int_{-T / 2}^{T / 2} g\left(w_{m k}, w_{m k}^{\prime}\right) e^{-i \omega_{n} t} d t
$$

Finally, we get the series $\left\{c_{n k}\right\}$ as the following:

$$
c_{n(k+1)}= \begin{cases}\frac{\left(\omega_{n}^{2}+P_{n}\right) c_{n k}-F_{n}-\mathcal{F}_{n k}}{\omega_{0}^{2}+i \beta \omega_{n}} & \text { if } 0 \leq|n| \leq N_{0} \\ \frac{\left(\omega_{0}^{2}+i \beta \omega_{n}\right) c_{n k}+F_{n}+\mathcal{F}_{n k}}{\omega_{n}^{2}+P_{n}} & \text { if } N_{0}<|n| \leq m\end{cases}
$$

The last equation defines a recurrent sequence $\left\{c_{n k}\right\}$ in $k$. If this sequence $\left\{c_{n k}\right\}$ converges to $\left\{c_{n}\right\} \forall n$ when $k \rightarrow \infty$, by replacing this series $c_{n k}, c_{n(k+1)}$ by its limit $c_{n}$, we find once again equation (17). Hence, this sequence converges to the solution of (17). By consequence, we can rebuild approximations of the response from (19) by using the sequence $\left\{c_{n k}\right\}$ when the value of $k$ is large enough. In the next section, we will use this formulation to calculate the response of the sleeper on different foundations. 


\section{EXAMPLES}

\subsection{Linear foundation}

Let's consider a foundation with a linear constitution law given by:

$$
f(w)=k_{2} w+\eta_{2} w^{\prime}
$$

In this case, the integral in equation (17) can be calculated analytically as following:

$$
\frac{1}{T} \int_{-T / 2}^{T / 2} g\left(w, w^{\prime}\right) e^{-i \omega_{n} t} d t=\int_{-T / 2}^{T / 2} \frac{k_{2} w+\eta_{2} w^{\prime}}{T M} e^{-i \omega_{n} t} d t=\left(\frac{k_{2}}{M}+\frac{i \eta_{2} \omega_{n}}{M}\right) c_{n}
$$

Thus, equation (17) has an analytic solution given by:

$$
c_{n}=\frac{F_{n}}{\omega_{n}^{2}+P_{n}-\omega_{0}^{2}-i \beta \omega_{n}-\left(k_{2}+i \eta_{2} \omega_{n}\right) / M}
$$

Now we calculate the solution of (17) by the numerical method. We need to verify that series $\left\{c_{n k}\right\}$ defined by (21) converges also to the analytic solution. By injecting function $f\left(w, w^{\prime}\right)$ in equation (22) into equation (20), we get:

$$
\mathcal{F}_{n k}=\left(\frac{k_{2}}{M}+\frac{i \eta_{2} \omega_{n}}{M}\right) c_{n k}
$$

Thus, equation (21) becomes:

$$
c_{n(k+1)}= \begin{cases}\frac{\left[\omega_{n}^{2}+P_{n}-\left(k_{2}+i \eta_{2} \omega_{n}\right) / M\right] c_{n k}-F_{n}}{\omega_{0}^{2}+i \beta \omega_{n}} & \text { if } 0 \leq|n| \leq N_{0} \\ \frac{\left[\omega_{0}^{2}+i \beta \omega_{n}+\left(k_{2}+i \eta_{2} \omega_{n}\right) / M\right] c_{n k}+F_{n}}{\omega_{n}^{2}+P_{n}} & \text { if } N_{0}<|n| \leq m\end{cases}
$$

We see that:

$$
c_{n(k+1)}-c_{n}= \begin{cases}\frac{\omega_{n}^{2}+P_{n}-\left(k_{2}+i \eta_{2} \omega_{n}\right) / M}{\omega_{0}^{2}+i \beta \omega_{n}}\left(c_{n k}-c_{n}\right) & \text { if } 0 \leq|n| \leq N_{0} \\ \frac{\omega_{0}^{2}+i \beta \omega_{n}+\left(k_{2}+i \eta_{2} \omega_{n}\right) / M}{\omega_{n}^{2}+P_{n}}\left(c_{n k}-c_{n}\right) & \text { if } N_{0}<|n| \leq m\end{cases}
$$

Here $c_{n}$ is the analytical solution in (23). The last equations are geometric sequences which converge to $c_{n}$ if and only if:

$$
\begin{cases}\left|\frac{\omega_{n}^{2}+P_{n}-\left(k_{2}+i \eta_{2} \omega_{n}\right) / M}{\omega_{0}^{2}+i \beta \omega_{n}}\right|<1 & \text { if } 0 \leq|n| \leq N_{0} \\ \left|\frac{\omega_{0}^{2}+i \beta \omega_{n}+\left(k_{2}+i \eta_{2} \omega_{n}\right) / M}{\omega_{n}^{2}+P_{n}}\right|<1 & \text { if } N_{0}<|n| \leq m\end{cases}
$$

Therefore, if $N_{0}$ is chosen such that the last inequalities are satisfied, we have proved that the numerical method converges to the analytic solution.

Figure 3 shows the results of the analytical and numerical methods for a railway track (type UIC60) with parameters given in table 1. The numerical method gives a good approximation of the analytical solution after 15 iterations. In fact the response corresponding to a linear foundation (22) with parameters $k_{2}=20 \mathrm{MNm}^{-1}$ and $\eta_{2}=0.2 \mathrm{MNsm}^{-1}$. 


\begin{tabular}{lcrl}
\hline Content & Notation & Value & Unite \\
\hline Rail mass & $\rho S$ & 60 & $\mathrm{kgm}^{-1}$ \\
Rail stiffness & $E I$ & 6.3 & $\mathrm{MNm}^{2}$ \\
Train speed & $v$ & 45 & $\mathrm{~ms}^{-1}$ \\
Charge of a wheel & $Q$ & 75 & $\mathrm{kN}$ \\
Block mass & $M$ & 100 & $\mathrm{~kg}$ \\
Sleeper length & $L$ & 0.6 & $\mathrm{~m}$ \\
Length of boogie & $D$ & 3 & $\mathrm{~m}$ \\
Length of wagon & $H$ & 18 & $\mathrm{~m}$ \\
Stiffness & $k_{1}$ & 220 & $\mathrm{MNm}^{-1}$ \\
Damping coefficient & $\eta 1$ & 1.0 & $\mathrm{MNsm}^{-1}$ \\
\hline
\end{tabular}

Table 1: Parameters of a linear railway track

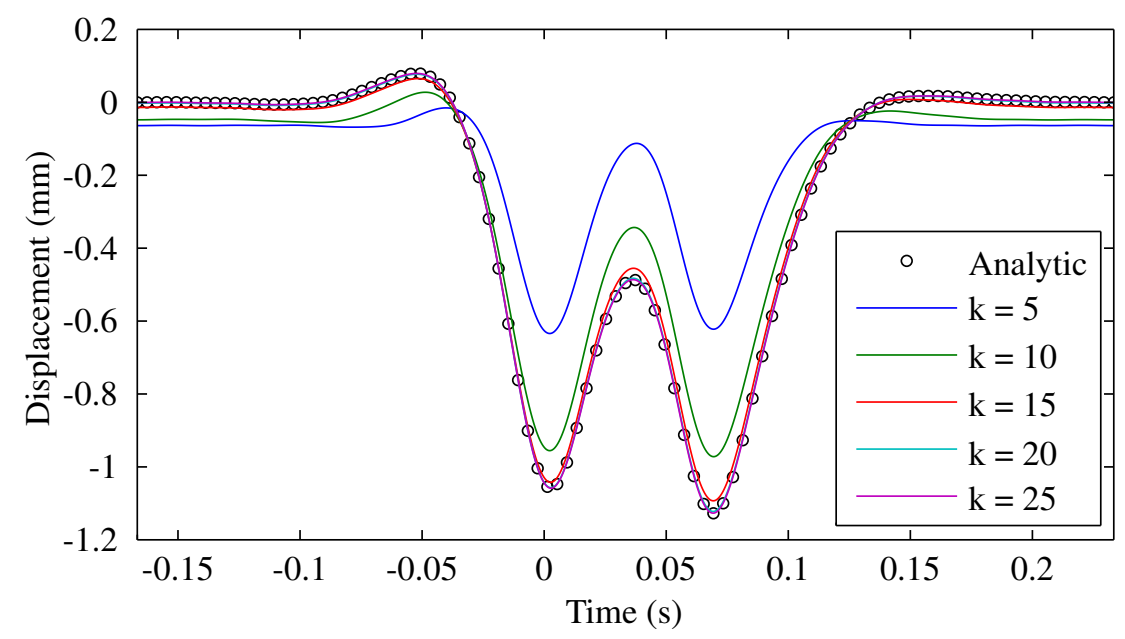

Figure 3: Displacement of a sleeper on a linear foundation by analytical and numerical method

\subsection{Bilinear foundation}

Now a bilinear foundation is considered with two different stiffness for compression and tension. Such a constitutive law can be described by the following function:

$$
f\left(w, w^{\prime}\right)= \begin{cases}k_{2}^{+} w+\eta_{2} w^{\prime} & \text { if } w<0 \\ k_{2}^{-} w+\eta_{2} w^{\prime} & \text { if } w \geq 0\end{cases}
$$

Here we compute the response of the railway sleeper by the numerical method and we investigate the convergence of this response when increasing the number of iterations and harmonics. The upper graph in figure 4 shows the results of the numerical method with different number of harmonics (while the number of iterations $k=100$ remains the same). We see that when the number of harmonics is bigger than 10, the response converges well (the variation is very small). We find again the convergence of the response with different numbers of iteration with $m=15$ (see the bottom graph in figure 4). Here, the calculation is taken with a railway track given by table 1 and the foundation parameters $k_{2}^{+}=20, k_{2}^{-}=10 \mathrm{MKm}^{-1}$.

For $m=15, k=100$, we now calculate the response for different tension stiffness in order to study the effect of this nonlinear parameter. Figure 5 shows these responses for different 

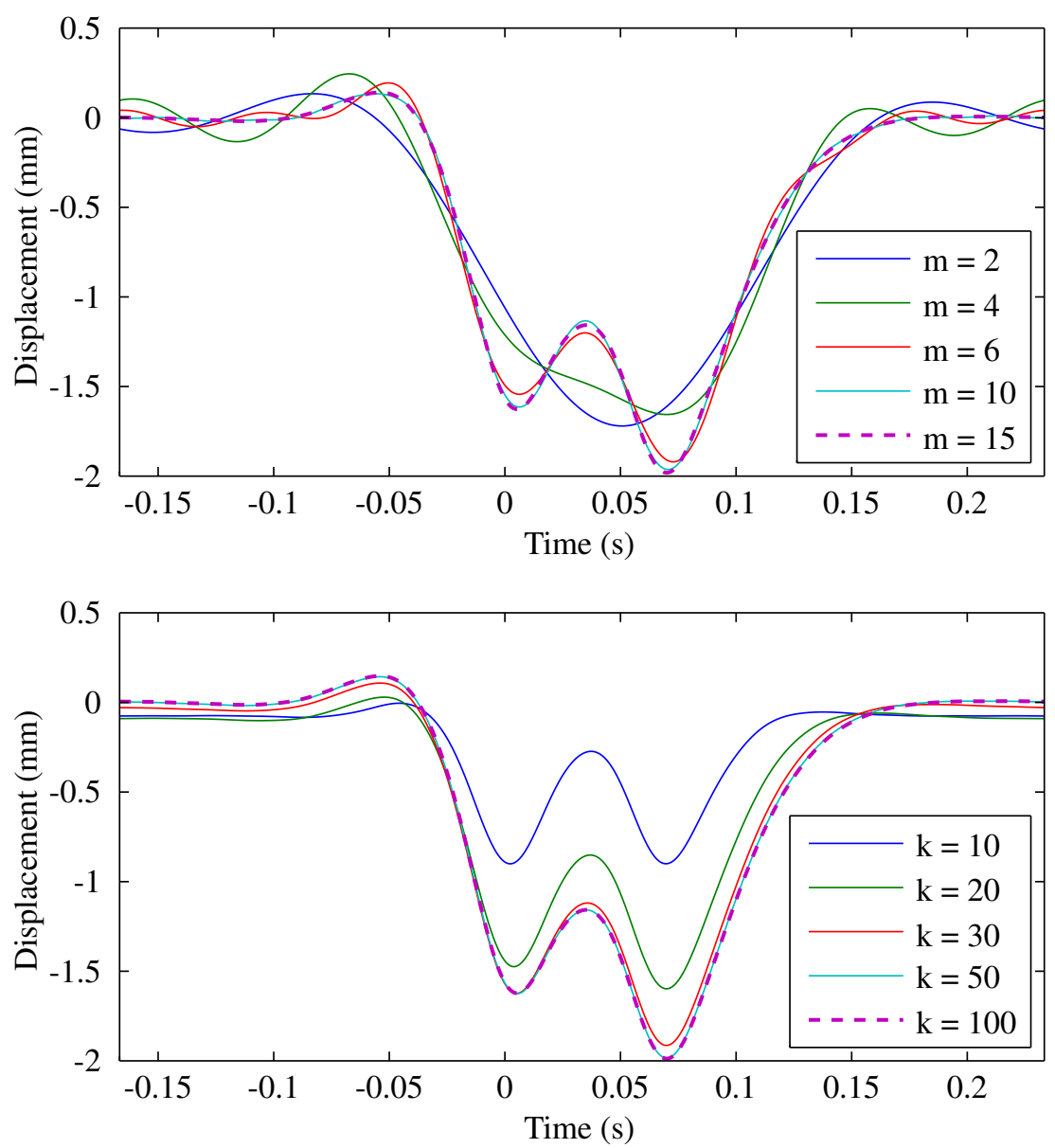

Figure 4: Displacement of a sleeper on a bilinear foundation by numerical method with different numbers of harmonics $m$ (upper figure) and iterations $k$ (lower figure)

$\operatorname{ratios} e=k_{2}^{-} / k_{2}^{+}$.

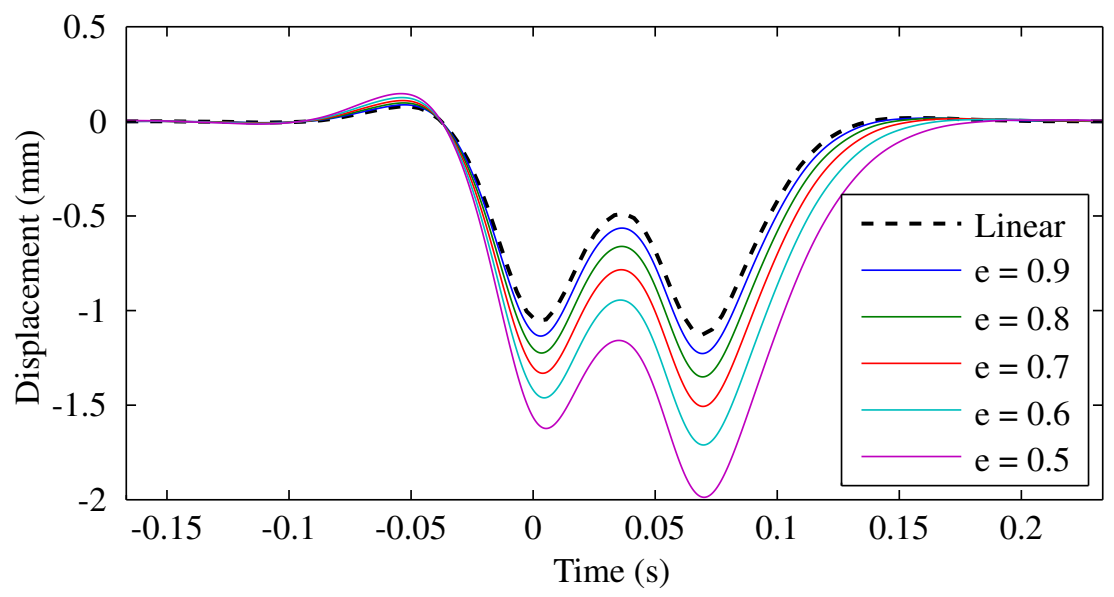

Figure 5: Displacement of a sleeper on bilinear foundations 


\subsection{Nonlinear foundation}

In this section, a nonlinear foundation with a cubic term in the stiffness is considered:

$$
f\left(w, w^{\prime}\right)=\eta_{2} w^{\prime}+k_{2} w+\varepsilon k_{3} w^{3}
$$

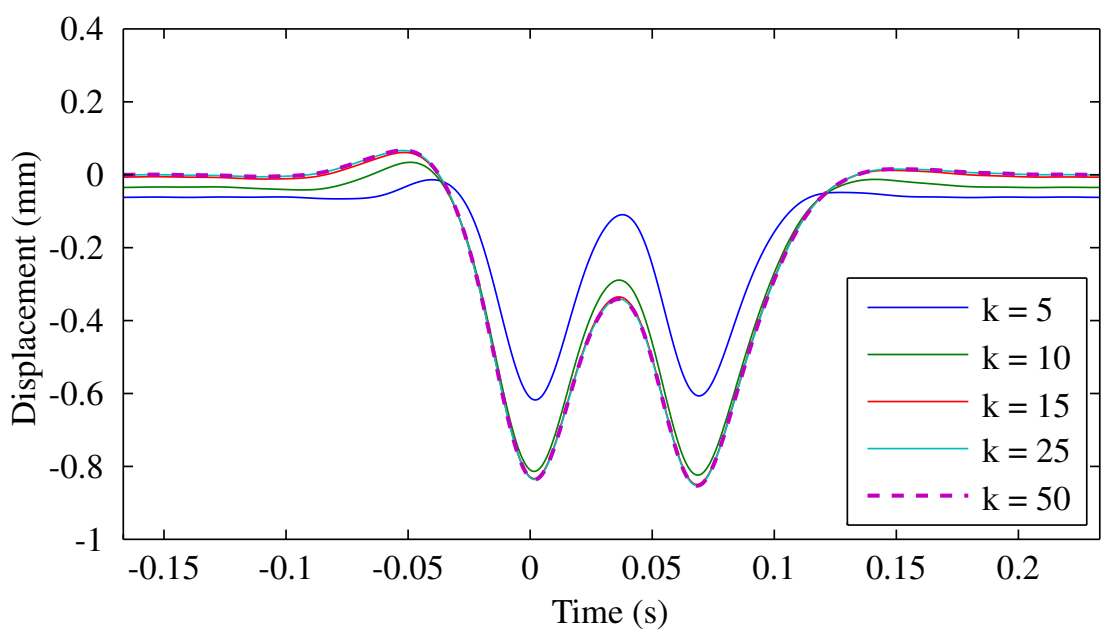

Figure 6: Displacement of a sleeper on a nonlinear elastic foundation by numerical method with different numbers of iterations

The response is calculated for different numbers of iterations $k$ with $m=15$ in order to study the convergence of the method. Figure 6 shows the convergence for $k \geq 15$. Here we take $k_{2}=20 \mathrm{MNm}^{-1}, k_{3}=20 \mathrm{kNmm}^{-3}$ and $\varepsilon=0.8$. The effect of the nonlinear parameter $\varepsilon$ is also investigated in figure 7 where the amplitude of the displacement decreases when the nonlinear force increases.

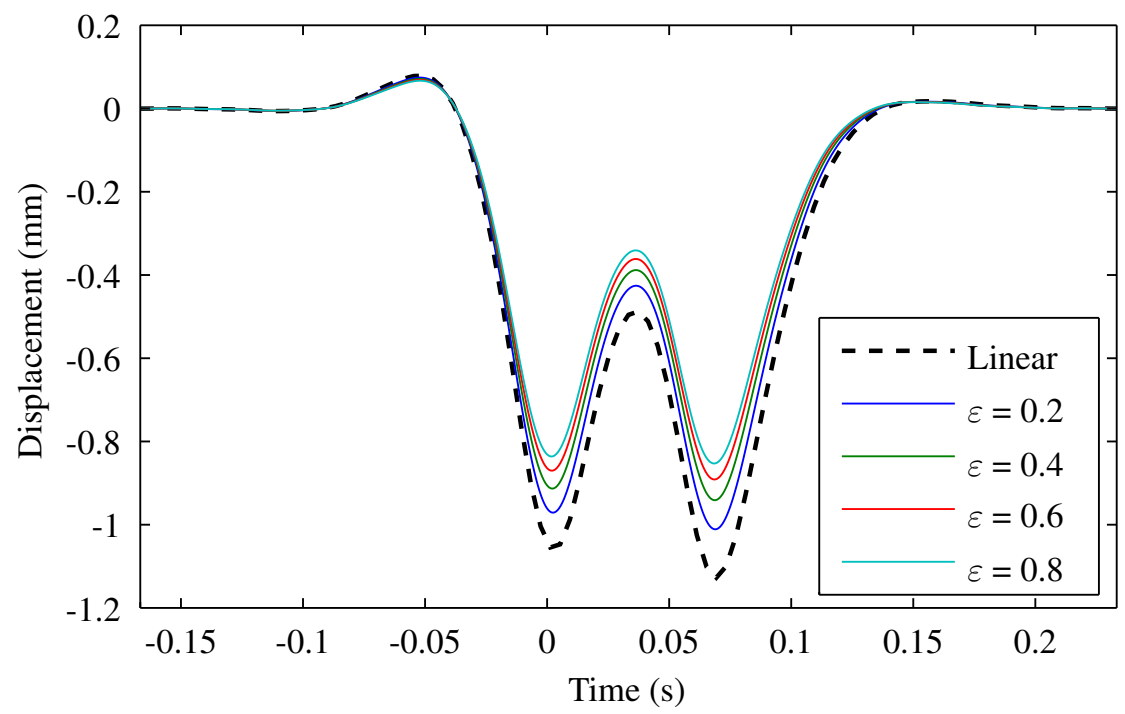

Figure 7: Displacement of a sleeper on nonlinear foundations 


\section{CONCLUSION}

A semi-analytic model for periodically supported beams has been developed and applied for the response of railway sleepers on different kinds of foundations. In linear cases, this method is proved to converge to the analytical solution. For other cases, this method is a simple way to approximate the response of railway tracks on complex foundations.

\section{References}

[1] T. Hoang, D. Duhamel, G. Foret, H. Yin, P. Joyez, R. Caby, Dynamical response of railway tracks in tunnel, 11th World Congress on Computational Mechanics (WCCM XI - ECCM $V$ - ECFD VI), Barcelona, Spain, 20-25 July 2014.

[2] V. H. Nguyen, D. Duhamel, Finite element procedures for nonlinear structures in moving coordinates. part ii: Infinite beam under moving harmonic loads, Computers and Structures, 86, 2056-2063, 2008.

[3] J.-S. Chen, Y.-K. Chen, Steady state and stability of a beam on a damped tensionless foundation under a moving load, International Journal of Non-Linear Mechanics, 46(1), 180-185, 2011.

[4] H. Ding, L.-Q. Chen, S.-P. Yang, Convergence of Galerkin truncation for dynamic response of finite beams on nonlinear foundations under a moving load, Journal of Sound and Vibration, 331 (10), 2426-2442, 2012.

[5] E. Sapountzakis, A. Kampitsis, Nonlinear response of shear deformable beams on tensionless nonlinear viscoelastic foundation under moving loads, Journal of Sound and Vibration, 330 (22) 5410-5426, 2011.

[6] P. C. Jorge, F. Simoes, A. P. da Costa, Finite element dynamics analysis of beams on nonuniform nonlinear viscoelastic foundations under moving loads, 9th Intenational Conference on Structural Dynamics (EURODYN2014), 2014.

[7] Y. Dugush, M. Eisenberger, Vibrations of non-uniform continuous beams under moving loads, Journal of Sound and Vibration, 254 (5), 911-926, 2002.

[8] M. Ansari, E. Esmailzadeh, D. Younesian, Frequency analysis of finite beams on nonlinear KelvinVoight foundation under moving loads, Journal of Sound and Vibration, 330 (7), 1455-1471, 2011.

[9] M. Kargarnovin, D. Younesian, D. Thompson, C. Jones, Response of beams on nonlinear viscoelastic foundations to harmonic moving loads, Computers \& Structures, 83 (23-24), 1865-1877, 2005.

[10] L. Fryba, Vibration of solids and structures under moving loads, Noordhoff International Publishing, 1972.

[11] L. Andersen, S. Nielsen, P. Kirkergaard, Finite element modelling of a infinite Euler beams on Kelvin foundations exposed to moving loads in convected co-ordinates, Journal of Sound and Vibration, 241 (4), 587-604, 2001. 
[12] X. Sheng, M. Li, C. J. C. Jones, D. J. Thompson, Vibration analysis of the continuous beam subjected to a moving mass, Journal of Sound and Vibration, 303, 873-894, 2007.

[13] M. Ichikawa, Y. Miyakawa, A. Matsuda, Vibration analysis of the continuous beam subjected to a moving mass, Journal of Sound and Vibration, 230 (3), 493-506, 2000.

[14] F. F. Calm, Dynamic analysis of beams on viscoelastic foundation, European Journal of Mechanics - A/Solids, 28 (3), 469-476, 2009.

[15] D. J. Mead, Free wave propagation in periodically supported, infinite beams, Journal of Sound and Vibration, 11 (2), 181-197, 1970.

[16] D. J. Mead, Wave propagation in continuous periodic structures: research contributions from southampton, Journal of Sound and Vibration, 190 (3), 495-524, 1996.

[17] X. Sheng, C. Jones, D. Thompson, Response of infinite periodic structure to moving or stationary harmonic loads, Journal of Sound and Vibration, 282, 125-149, 2005.

[18] P. M. Belotserkovskiy, On the oscillation of infinite periodic beams subjected to a moving concentrated force, Journal of Sound and Vibration, 193 (3), 705-712, 1996.

[19] A. V. Metrikine, K. Popp, Vibration of a periodically supported beam on an elastic halfspace, European Journal of Mechanics A/Solid, 18, 679-701, 1999.

[20] M. A. Foda, Z. Abduljabbar, A dynamic green fuction formulation for the response of a beam structure to a moving mass, Journal of Sound and Vibration, 210 (2), 295-306, 1998.

[21] A. V. Vostroukhov, A. Metrikine, Periodically supported beam on a visco-elastic layer as a model for dynamic analysis of a high-speed railway track, International Journal of Solids and Structures, 40, 5723-5752, 2003.

[22] A. H. Nayfeh, Introduction to perturbation techniques, Wiley Classics Library Edition, 1993.

[23] A. H. Nayfeh, D. T. Mook, Nonlinear oscillations, Wiley Classics Library Edition, 1995. 